\title{
Subadditivity Tests for Network Separation with an Application to U.S. Railroads
}

\author{
MARC IVALDI * \\ Toulouse School of Economics \\ GERARD MCCULLOUGH \\ Department of Applied Economics, University of Minnesota
}

\begin{abstract}
We describe a pair of empirical tests that can be used to evaluate the technological feasibility of separating a vertically integrated network monopoly into a common infrastructure component and competing operating components. We implement the tests with a Generalized McFadden cost function that is globally concave in input prices and permits the assignment of zero output values without losing its flexibility properties. The tests shed light on the respective roles of regulation and competition policy. We illustrate them with an analysis of U.S. freight railroads for the period 19782001 and find both vertical and horizontal economies of scope.
\end{abstract}

\section{Introduction}

There are two basic policy alternatives to state operation for dealing with vertically integrated network firms that exhibit characteristics of natural monopoly. One is regulation, which involves the monitoring of firms by either independent regulatory agencies or government administrations; the other is competition policy, a set of government activities ranging from antitrust enforcement to network separation and mandated access to establish competition on previously monopolized networks. Though there may be cases where competition policy is a substitute for regulation, the two forms of network oversight often appear as policy complements with the exact combination dictated by technological factors, potential transactions costs, public service considerations and political traditions. ${ }^{1}$

The best known empirical assessment of network natural monopoly was proposed by David S. Evans and James J. Heckman (1984), who used a translog cost function to test whether Bell System costs for the period 1947-1977 were subadditive. Their finding that the Bell System was not a natural monopoly was disputed by Lars-Hendrik Röller (1990), who analyzed the same data with a quadratic cost function but affirmed by Richard T. Shin

\footnotetext{
* Contact Author. Mailing address: University of Toulouse, Manufacture des Tabacs, 21 Allée de Brienne, 31000 Toulouse, E-mail: marc.ivaldi@,TSE-fr.eu

${ }^{1}$ See EC (2000) for a discussion of the relationship between optimal regulation and competition policy and for descriptions of restructuring experiments in various network industries.
} 
and John S. Ying (1992), who used a translog cost function and 1976-1983 data to test for subadditivity. All three papers acknowledged the limitations imposed by the functional forms they employed. Proper econometric testing for subadditivity requires a cost function which is globally concave in input prices and permits the assignment of zero output values without losing its flexibility properties. The quadratic fails the first requirement while the translog fails both.

This paper focuses on technological aspects of vertical integration of networks such as electricity and railroads, where service-related operations and infrastructure-related maintenance activities are the two main sources of costs. These networks pose a special challenge for competition advocates because they may resist the unbundling of vertically integrated activities into a common infrastructure entity and competing operating entities. If, for example, there are vertical economies of scope between operations and infrastructure, there may be a loss of vertical efficiency if the two are separated. ${ }^{2}$ Or, if there are economies of joint production among operational activities, then firms operating on network infrastructure may still exhibit characteristics of natural monopoly. ${ }^{3}$

We propose to address these issues by applying a pair of empirical tests that can be used to evaluate the technological feasibility of separating an integrated network monopoly into infrastructure and operating components. We show how the tests can be implemented with a multiproduct Generalized McFadden cost function which is globally concave in input prices and accommodates zero outputs. Thus, using available data on integrated firms and known concepts and techniques, we are able to provide a measure of the economic stakes involved in a vertical divestiture.

Section I introduces the two tests - an infrastructure separation test to establish whether the cost function is subadditive between network operations and infrastructure, and an operational separation test to establish whether there is subadditivity across types of operations. Section II shows how the tests can be implemented econometrically using the Generalized McFadden. Section III illustrates the tests with an evaluation of recent competition proposals for U.S. freight railroads. To do this, we estimate a multiproduct GM cost function that includes both operational and infrastructure outputs. Our empirical results support and extend the work of Bitzan (1999) and Ivaldi and McCullough (2001) who find vertical economies of scope between rail infrastructure and operations and horizontal economies among on-rail operations. Section IV discusses the broad applicability of our tests to network industries, the implications of our findings for rail policy in the U.S., and the potential relevance for restructuring of rail systems in Europe and elsewhere.

\section{Two tests of subadditivity}

Scale and scope are the standard measures to describe production economies but these are only descriptive measures. The relevant technological measure from a policy perspective is subadditivity of the cost function. It is subadditivity (and not scale or scope) which finally

\footnotetext{
${ }^{2}$ Kaserman and Mayo (1991) find vertical economies between the generation stage and transmission/distribution stages of electricity production.

${ }^{3}$ Bitzan (1999) and Ivaldi and McCullough (2001) find horizontal economies among differentiated operating outputs on U.S. freight railroads. Pittman (2005) provides a detailed discussion of the issues involved in separating rail infrastructure from operations.
} 
determines whether an output vector $y$ can be produced more cheaply by a single firm than by any group of firms. ${ }^{4}$ This, in turn, determines whether a technology is a natural monopoly on a given territory or market and potentially subject to some form of government intervention.

Baumol's (1977) definition of cost subadditivity for multiproduct production is as follows.

Definition of Cost Subadditivity. Let $C(y)$ represent the total costs associated with production of output vector $y$. The overall network cost function $C(y)$ is subadditive if and only if for any and all vectors $y^{i} \neq y$ s.t. $\Sigma y^{i}=y, C(y)<\Sigma C\left(y^{i}\right)$, where $i$ is an index of firms.

If $C(y)$ is subadditive and $y$ is significant relative to market demand, there may be a need for government oversight. Oversight can take the form of regulation and/or competition policy. One way to establish competition in this context is through government-run auctions for service over given territories and benchmarking among firms competing "for the market". Competition can also be established through separation ("unbundling") of the network monopoly into a regulated or publicly supported infrastructure entity and a set of operating firms with access to infrastructure that compete "on-the-market". Underlying a policy of "on-the-market" competition, however, are two important technological assumptions which can be evaluated using the subadditivity criterion.

Definition of Infrastructure Separation. Let $y^{S}$ and $y^{T}$ represent an orthogonal partition of the output vector $y$ into operational activities $\left(y^{S}\right)$ and infrastructure-related activities $\left(y^{T}\right)$. The cost function is subadditive between operations and infrastructure costs if and only if $C(y)<C\left(y^{S}, 0\right)+C\left(0, y^{T}\right)$.

If the necessary and sufficient conditions for infrastructure separation are met, that is, if there are vertical economies of scope between operations and infrastructure, there could be a loss of technical efficiency if infrastructure and operations are separated. This may be offset by competition effects, in particular by lowering the degree of allocative inefficiency; but, if the loss of technical efficiency is large, optimal regulation of the integrated monopoly or franchise competition for the market are the relevant policies. (Partial disintegration in which the infrastructure provider is also one of the on-market competitors is another competitive solution.)

Definition of Operational Separation. Assume infrastructure separation. The cost function for operations is subadditive between operations if for any and all vectors $y^{i} \neq y$ s.t $\Sigma y^{i}=y^{S}, C\left(y^{S}, 0\right)<\Sigma C\left(y^{i}, 0\right)$.

\footnotetext{
${ }^{4}$ Scale and scope are necessary but not sufficient conditions for subadditivity. See Panzar (1989) for an analysis of the relationship of subadditivity to economies of scale and scope.
} 
Based on this definition, we can test whether there are horizontal economies of joint production among operational activities. If the operational separation test shows that the cost function $C\left(y^{S}, 0\right)$ is not subadditive, this is a technological indication that competition between operating companies "on the market" can be effective. If $C\left(y^{S}, 0\right)$ is subadditive, then a) there may be a loss of technical efficiency if operations are forced to separate, and b) it is reasonable to expect that operations "on the market" will be concentrated. Thus, there may be a need for optimal regulation of operating entities after operations are separated from infrastructure.

\section{Implementation with the Generalized McFadden}

We test for subadditivity using a modification of the Generalized McFadden (GM herein) cost function that was introduced by Diewert and Wales (1987) and derived from McFadden (1978). The primary advantage of this function is that the domain of approximation is set by the analyst along with the estimation of parameters. However, to our knowledge, there is no general form in the multiple-output case. Kumbhakar (1994) was the first to propose a plausible extension but one could envision many other generalizations, thanks to the structure of the Generalized McFadden cost function itself. Based on our experience at the estimation stage, we propose to extend the Kumbhakar's form by allowing for a third order approximation of the functional relationship of input prices, outputs and technological constraints. In this way, we enlarge even more the flexibility of the approximated cost function.

Let $w$ be an $n$-dimensional vector of input prices, $t$ a $q$-dimensional vector of quasifixed technological factors, and $y$ an $r$-dimensional vector of outputs. Define $z$ as the $m$ dimensional vector $(m=q+r)$ that includes $y$ and $t$. The GM conditional cost function is

$$
C^{C}=\alpha^{\prime} w+0.5 \frac{w^{\prime} \Delta w}{\theta^{\prime} w}\left(\beta^{\prime} y\right)^{2}+w^{\prime} \Lambda z+0.5\left(\theta^{\prime} w\right) z^{\prime} \Gamma z
$$

where $\alpha$ is an unconstrained $n$-dimensional parameter vector, $\Delta$ an $n \times n$ symmetric parameter matrix, $\Lambda$ an $n \times m$ parameter matrix of nonnegative elements, $\Gamma$ an $m \times m$ symmetric parameter matrix, and $\theta$ is an $n \times l$ vector of fixed parameters. In most applications of the type we are concerned with here, it is reasonable to assume that network size and firm capital levels are quasi-fixed. This is why we propose a conditional cost function in which the $w$-vector includes only the prices of variable inputs and the $t$ vector includes a measure of quasi-fixed capital. ${ }^{5}$

\footnotetext{
${ }^{5}$ Let $k$ be a measure of quasi-fixed capital. In this case the total cost function is $C=\alpha^{\prime} w+0.5 \frac{w^{\prime} \Delta w}{\theta^{\prime} w}\left(\beta^{\prime} y\right)^{2}+w^{\prime} \Lambda z+0.5\left(\theta^{\prime} w\right) z^{\prime} \Gamma z+\rho k$ where $\rho$ is the price of capital and $k$ is an element of $z$.
} 
For $C^{C}$ to provide a second order (flexible) approximation to an arbitrary conditional cost function $C^{*}$, it must contain $(n+m)(n+m+1) / 2$ free parameters. As the cost function in (1) contains $(n+m)(n+m+1) / 2+m$ parameters, it is flexible. It is also homogeneous and monotonic in $w$, and it is concave in $w$ if the estimated matrix $\Delta$ is negative semi definite. If not, concavity can be imposed by setting $\Delta=-B D B^{\prime}$ where $B$ is a lower triangular matrix with the sum of its diagonal elements equal to 1 and $D$ is a nonnegative diagonal matrix. ${ }^{6}$

To estimate $C^{C}$, we use the vector of $n$ factor demands derived by applying Shephard's lemma. This $n$-dimensional vector containing all of the cost function parameters is

(2) $X=\alpha+\left[\frac{\Delta w}{\theta^{\prime} w}-0.5 \frac{\left(w^{\prime} \Delta w\right) \theta}{\left(\theta^{\prime} w\right)^{2}}\right]\left(\beta^{\prime} y\right)^{2}+\Lambda z+0.5 \theta\left(z^{\prime} \Gamma z\right)$.

To evaluate subadditivities, we begin by using the estimated parameters from (2) to identify what we call the start-up costs, that is, all costs that would be incurred at zero output levels (or incurred before starting production.). ${ }^{7}$ We then aggregate up from this base, comparing the projected cost levels that result as the level and composition of outputs are changed. Projected start-up costs are

$$
\hat{C}^{0}=w^{\prime}\left(\hat{\alpha}+\hat{\Lambda}_{t}{ }^{\prime} t+0.5 \theta t^{\prime} \hat{\Gamma}_{t} t\right)
$$

where the term in parentheses is the vector of projected factor demands in (2) but includes only the technological components (and not the output-related components) of $\Lambda, \Gamma$, and $z$.

Projected variable costs for the output vector $y^{*}$ are

$$
\hat{C}^{V}=w^{\prime}\left\{\left[\frac{\hat{\Delta} w}{\hat{\theta}^{\prime} w}-0.5 \frac{\left(w^{\prime} \hat{\Delta} w\right) \hat{\theta}}{\left(\hat{\theta}^{\prime} w\right)^{2}}\right]\left(\hat{\beta}^{\prime} y\right)^{2}+\hat{\Lambda}_{z^{*}}{ }^{\prime} z^{*}+0.5 \theta\left(z^{*} \hat{\Gamma}_{z^{*}} z^{*}\right)\right\}
$$

where the term in braces is the vector of projected factor demands but with those elements of $y$ that do not belong to $y^{*}$ set to zero and with the elements of $t$ entering only to the extent that they interact with $y^{*}$ elements. Projected conditional costs of producing $y^{*}$ are $\hat{C}^{C^{*}}=\hat{C}^{0}+\sum_{h} \hat{C}_{h}^{V}$ where $h$ is the number of separate firms into which the network is unbundled.

The ability to project start-up cost separately from variable cost is an important feature of this specification of the Generalized McFadden specification. As we simulate changes in cost that result from combining or separating network activities, we are able to distinguish cost effects that are purely output-related from those that may result from a duplication of

\footnotetext{
${ }^{6}$ This parameterization is from Wiley, Schmidt and Bramble (1973).

${ }^{7}$ In our view, start-up costs include sunk and fixed costs, that is to say, costs that are lost if operations are eventually closed and costs that are transferable or tradable.
} 
start-up costs. For example, we may expect $C^{C}\left(y_{1}, 0\right)+C^{C}\left(0, y_{2}\right)$ to have higher startup costs than $C^{C}\left(y_{1}, y_{2}\right)$ but we would probably not expect start-up costs to double necessarily. The above specification allows us to simulate the effect of different start-up costs on conditional costs using

$$
\hat{C}^{C}=\delta \hat{C}^{0}+\sum_{h} \hat{C}_{h}^{V}
$$

where $\delta$ is the degree to which start-up costs are duplicated when production is unbundled.

\section{$4 \quad$ Empirical application to U.S. freight railroads}

The U.S. railroad industry consists primarily of private sector freight railroads operating under a relaxed regulatory scheme imposed by the Staggers Rail Act of $1980 .{ }^{8}$ Overall output levels (ton-miles) have remained fairly constant since Staggers and overall rate levels have declined but the number of Class I railroads has also dropped from 38 to eight. ${ }^{9}$ The consolidation trend has led some legislators to call for a national system of open rail access. Regulators at the Surface Transportation Board have favored a limited access solution, requiring that tenant railroads be given the right to use host railroad tracks only in cases where shippers are shown to be "captive" to the host.

In this section, we apply the subadditivity tests to U.S. freight railroads using the GM functional form. The data that we use are from regulatory reports filed by major U.S. freight railroads for the period 1978-2001. The firms are listed in Appendix Table A1. ${ }^{10}$ All together the data set contains 297 observations.

The specification that we use differs from other rail cost functions in that we view the infrastructure-related activities of the firm as a variable output which imposes costs directly and which interacts with other (operational) outputs. ${ }^{11}$ Our model assumes a vertical production process in which quasi-fixed land and other inputs (fuel, materials, labor and equipment) are first transformed into infrastructure outputs and then into differentiated car-miles. This allows us to investigate the technological aspects of vertical and horizontal integration. This also avoids a potentially strong collinearity problem that could be present in the cost function for integrated network firms when the definitions of capital and infrastructure services are not precisely stated.

Our general rail cost model is

$$
C=C^{C}\left(y_{B}, y_{E}, y_{I}, w_{L}, w_{E}, w_{F}, w_{M} ; H, R, T, U, \theta\right)+\rho R
$$

\footnotetext{
${ }^{8}$ Intercity passenger trains operated by the National Railroad Passenger Corp. (AMTRAK) account for less than one percent of annual rail revenues.

${ }^{9}$ See Wilson (1997) and Ellig (2002) for discussions of rail performance since deregulation.

${ }^{10}$ More detailed explanation of the choice of variables and a description of their sources and construction are in Ivaldi and McCullough (2001) and the references therein.

${ }^{11}$ In most rail cost studies, such as Berndt et al (1993), infrastructure is treated as a quasi-fixed input and represented by a monetary measure of way and structures capital. Wilson (1997) is an exception.
} 
where

$C=$ total costs,

$\mathrm{C}^{\mathrm{C}}=$ conditional costs

$y_{B}=$ car-miles of bulk traffic (that is, open hopper, closed hopper, tank),

$y_{E}=$ car-miles of general traffic (that is, intermodal, auto-carriers, gondolas and box cars),

$y_{I}=$ replacement ties installed in a given year,

$w_{L}=$ index of labor prices,

$w_{E}=$ index of equipment prices,

$w_{F}=$ index of fuel prices,

$w_{M}=$ index of material prices and other input prices,

$H=$ average length of haul,

$R=$ miles of road operated,

$T=$ counter for years,

$U=$ percent of car-miles moving in unit trains,

$\theta=$ vector of fixed effect parameters

$\rho=$ opportunity cost of capital.

Here, the fixed capital quantity is land measured by the number of miles of road $(R)$, while variables $H$ and $U$ allow us to differentiate railroads in terms of their network structures. The number of ties replaced in a year provides a measure of the usage of tracks and, as such, is a measure of the activity of the infrastructure department in railroads. In addition, note that there are two operational outputs and four variables inputs.

The system that we estimate includes four factor demand equations defined by (2) above and three additional demand equations for the endogenous output variables $y_{B}, y_{E}$ and $y_{I}{ }^{12}$ The system is estimated using full information maximum likelihood with a correction for firm-level fixed effects within the factor demand equations. This is done by fixing the values of the $\theta$ parameters at the average values of each firm's input quantities. ${ }^{13}$

The estimated cost model is globally concave in $w$ and the full parameter set is consistent with the results of earlier rail cost models such as Wilson (1997), Bitzan (1999) and Ivaldi and McCullough (2001). The general regression results are presented in Appendix Table A2. Of particular interest are the second-order output-related parameter estimates shown in Table 1. ${ }^{14}$ These show significant cost complementarities between bulk operations $\left(y_{B}\right)$ and general freight $\left(y_{E}\right)$ operations, and between infrastructure outputs $\left(y_{I}\right)$ and both of the operational outputs. Our interpretation is that these complementarities result from the higher capabilities that railroads develop as traffic volumes increase and as firms become skilled in complex scheduling of trains, locomotives and train crews and

\footnotetext{
12 There is a potential problem of output endogeneity because average freight prices are capped by the regulator and because these prices are related to costs and costs to output levels. The additional variables in the demand equations are annual system-wide population and system-wide coal consumption for each railroad. By introducing these demand equations, the estimation approach resembles an IV method.

${ }^{13}$ See Diewert and Wales, op. cit., p.49.

14 The full set of estimates is available on request from the authors.
} 
maintenance activities. ${ }^{15}$ These higher capabilities for commanding and controlling operations become available as "public inputs" for infrastructure activities and train operations. Interestingly though, we find no evidence of own-cost complementarities which suggests that U.S. railroads have exhausted the direct cost efficiencies associated with the movement of increasingly larger quantities of bulk and general freight traffic.

\begin{tabular}{llllll}
\hline Parameter & Estimate & T value & Parameter & Estimate & T value \\
\hline$w_{L}$ & -48.3201 & -0.11 & $w_{E} * y_{E}$ & 0.005984 & 4.58 \\
$w_{F}$ & 440.0777 & 2.98 & $w_{E} * y_{I}$ & 0.026104 & 0.03 \\
$w_{E}$ & 461.0521 & 0.73 & $w_{M} * y_{B}$ & 0.001764 & 3.78 \\
$w_{M}$ & -260.7760 & -1.69 & $w_{M} * y_{E}$ & 0.000780 & 2.48 \\
$w_{L} * y_{B}$ & 0.003626 & 2.90 & $w_{M} * y_{I}$ & -0.103770 & -0.47 \\
$w_{L} * y_{E}$ & 0.004406 & 5.18 & $y_{B} * y_{B}$ & $3.80 \mathrm{E}-13$ & 6.93 \\
$w_{L} * y_{I}$ & 0.812610 & 1.38 & $y_{E} * y_{E}$ & $2.78 \mathrm{E}-13$ & 8.74 \\
$w_{F} * y_{B}$ & 0.000165 & 0.34 & $y_{I} * y_{I}$ & $7.09 \mathrm{E}-08$ & 3.23 \\
$w_{F} * y_{E}$ & 0.000914 & 2.48 & $y_{B} * y_{E}$ & $-2.98 \mathrm{E}-13$ & -8.35 \\
$w_{F} * y_{I}$ & -0.111160 & -0.52 & $y_{B} * y_{I}$ & $6.56 \mathrm{E}-11$ & -2.46 \\
$w_{E} * y_{B}$ & -0.000320 & -0.17 & $y_{E} * y_{I}$ & $-2.95 \mathrm{E}-11$ & -1.37 \\
\hline
\end{tabular}

Table 1: McFadden first order price and second-order cross cost parameter estimates

We now use (3), (4), and (5) to conduct simulations of the type proposed by Evans and Heckman to evaluate single firm versus two-firm subadditivity. For infrastructure separation we test whether

$$
C^{C}\left(y_{B}, y_{E}, y_{I}\right) \leq \delta C^{0}+C^{V}\left(y_{B}, y_{E}, 0\right)+C^{V}\left(0,0, y_{I}\right)
$$

using the sample values of $w, y, t$ and $\theta$ for each of the 297 observations. For the twofirm scenarios on the right-hand side of (7) we allow the duplication of start-up costs to be proportional to single-firm start-up costs by the factor $\delta$ which takes values $1.0,1.33,1.66$, and 2.0.

For operational separation, we test whether

$$
C^{C}\left(y_{B}, y_{E}, 0\right) \leq \delta C^{0}+C^{V}\left(\alpha y_{B}, \beta y_{E}, 0\right)+C^{V}\left[(1-\alpha) y_{B},(1-\beta) y_{E}, 0\right]
$$

where the parameters $\alpha$ and $\beta$ take values $0,0.33,0.66$, and 1 , and where $\delta$ varies as in the first test.

The test results are summarized in Table 2. The results for infrastructure separation confirm that there are complementarities between infrastructure-related activities and train operations. The degree of start-up cost duplication plays a relatively small role in determining subadditivity. The results for operational separation suggest that there are

\footnotetext{
${ }^{15}$ See Ivaldi and McCullough (2001) for additional discussion of rail cost complementarities.
} 
also complementarities between types of freight service. Operational costs are subadditive for 93.7 percent of the cases even when there is no duplication of start-up costs. ${ }^{16}$

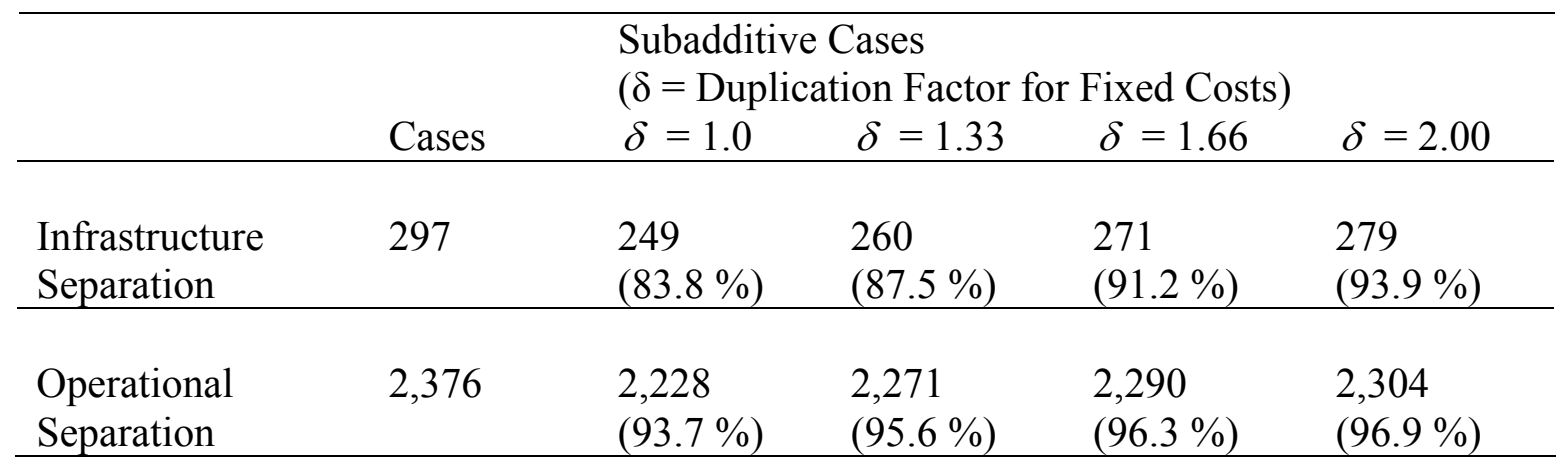

Table 2: One firm versus two firm subadditivity tests

The results for vertical separation of U.S. freight railroads are restated in Table 3 where we again use (3), (4) and (5) to estimate conditional costs for the average firm in our sample of 297 observations. We project these costs for an integrated firm scenario (current projected costs), a separated firms scenario where infrastructure is unbundled from operations but operations are integrated and a diversified firms scenario where infrastructure, bulk and general freight are all unbundled. For analytical simplicity, we assume that the diversifications are orthogonal and that are no adjustments in network $\operatorname{size}(R)$. We present results for limiting cases of no duplication of start-up costs $(\delta=1)$ and complete duplication $(\delta=2)$.

The projections suggest that the fully integrated firm would have a 20-40 percent cost advantage over a vertically separated system where the operating company provided bulk and general freight services. Even greater losses of efficiency may occur if bulk and general freight operations were unbundled. The projections indicate that a firm which combined the movement of bulk and general freight would have a 70 percent cost advantage over two separate firms, one of which moved only bulk and the other only general freight.

There are caveats that apply to Tables 2 and 3. First, with our sample of integrated firms, we cannot assess whether transactions costs associated with separated operations would be higher (or lower) than they are in integrated firms. ${ }^{17}$ Nor can we assess whether competition effects would offset the estimated loss of technical efficiency. Finally, the results are based on firm-level observations, thus comprise a within sample test of subadditivity and not a global test of natural monopoly. Our tests use sample values for the set of technological factors $t$, and $t$ includes a measure of network size $(R)$ for each firm

\footnotetext{
${ }^{16}$ We also used the Generalized McFadden to conduct Baumol's for the overall subadditivity of the rail cost function. Even without duplication of fixed costs $(\delta=1)$, we find overall costs subadditive in 9,300 of 9,504 possible cases (97.8 percent). We do not report these results in Table 2 because we do not give them much credence. The overall test here assumes that operations and infrastructure can be separated without regard to output proportions. Thus, for example, it compares whether combinations like $\mathrm{C}(\mathrm{yB}, \mathrm{yE}, .33 \mathrm{yI})+\mathrm{C}(0,0$, $.66 \mathrm{yI})$ are greater than $\mathrm{C}(\mathrm{yB}, \mathrm{yE}, \mathrm{yI})$ which does not seem relevant.

${ }^{17}$ Teece (1980) notes that transaction costs as well as technology significantly affect the "scope of enterprise".
} 
and year. In fact, we may expect network sizes to change as the vertical structure of firms within the industry changed and this would affect projected costs. Nevertheless, the results based on conditional costs are consistent with a natural monopoly hypothesis. ${ }^{18}$

\begin{tabular}{|c|c|c|c|c|c|}
\hline \multirow[b]{2}{*}{ Projected Costs } & \multirow[t]{2}{*}{ Integrated Firm } & \multicolumn{2}{|c|}{ Separated Firms } & \multicolumn{2}{|c|}{ Diversified Firms } \\
\hline & & $\delta=1$ & $\delta=2$ & $\delta=1$ & $\delta=2$ \\
\hline Fixed Cost & & 169,067 & 338,134 & 169,067 & 338,134 \\
\hline Infrastructure & & 217,410 & & 217,410 & \\
\hline $\begin{array}{l}\text { Operations } \\
\text { Bulk } \\
\text { General Freight } \\
\text { Subtotal }\end{array}$ & & $1,065,292$ & & $\begin{array}{l}823,799 \\
984,802 \\
1,808,601 \\
\end{array}$ & \\
\hline Total & $1,150,860$ & $1,451,769$ & $1,620,836$ & $2,195,080$ & $2,364,147$ \\
\hline
\end{tabular}

Table 3: Alternative scenarios

Note: Thousands of 1997 dollars.

\section{$5 \quad$ Conclusions}

Our analysis has focused on the technological determinants of network oversight for firms such as electric utilities and railroads which exhibit the characteristic of natural monopolies and have strong operational and infrastructure maintenance components. We propose a testing method based on the definition of cost subadditivity to measure the technical cost of unbundling network technologies into infrastructure components and operating components. We implement tests for infrastructure separation and operational separation with a Generalized McFadden cost function. We illustrate these tests with an application to U.S. freight railroads.

Our formal results should be useful not only to rail researchers but to analysts who are concerned with other network industries such as natural gas, electricity and water distribution. Regulators and legislators often assume that welfare can be improved by separating vertically-integrated networks to enhance competition but empirical researchers sometimes find evidence of vertical economies in these networks whose loss would reduce or negate welfare gains. ${ }^{19}$ Pittman (2005) notes that regulators have also encountered difficulties in implementing some separation policies. ${ }^{20}$ Our tests can be used ex ante to measure the technological challenge involved in a unbundling policy aimed at separating an integrated network into infrastructure and operating components. They can be implemented with a cost function that is globally concave in input prices that accommodates zero output levels without losing its flexibility and is able to project startup costs separately from the variable costs associated with particular output vectors.

\footnotetext{
${ }^{18}$ See the conclusion of Roller (1990) regarding Bell System natural monopoly.

${ }^{19}$ See, for example, Fraquelli, Piacenza and Vannoni (2005) for a recent discussion of electric utilities.

${ }^{20}$ Pittman writes that “...the [separation] model has not always worked out as well in practice as it has on the blackboard. In recent years it has become apparent that the model is more likely to be successful in some sectors than in others, and in some countries at some times than in other countries at other times" (p.181).
} 
Our empirical results have interesting implications for U.S. rail policy. Our simulations suggest first that there would be a 20-40 percent loss of technical efficiency if railroad freight operations were separated from infrastructure and an additional 70 percent loss of operational efficiency if on-rail operations were separated. In our view, this places a heavy burden of proof on proponents of separation to establish that a) separated firms could coordinate infrastructure and operations efficiently using market mechanisms, and/or b) the efficiency gains from on-rail competition would somehow offset the loss of vertical and horizontal efficiencies.

The potential implications of our empirical findings for rail restructuring efforts in Europe and elsewhere are less clear. European systems, which usually combine freight operations with a high level of passenger operations, have different technological characteristics than U.S. railroads. (See Footnote 8.) On the one hand, we may see stronger vertical economies between infrastructure and operations due to the complexity (and relative inflexibility) of passenger operations. On the other hand, we may not see horizontal economies between on-rail passenger and on-rail freight operations because of their qualitative differences. Careful delineation and interpretation of these effects is a subject for further research.

\section{$6 \quad$ References}

Baumol, W. J. (1977) "On the Proper Cost Tests for Natural Monopoly in a Multiproduct Industry," American Economic Review, 67: 43-57.

Berndt, Ernst R., Ann F. Friedlaender, Judy Shaw-Er Wang Chiang and Christopher A. Vellturo (1993) "Cost Effects of Mergers and Deregulation in the U.S. Rail Industry," Journal of Productivity Analysis, 4: 127-144.

Bitzan, John D. (1999) "The Structure of Railroad Costs and the Benefits/Costs of Mergers," Research in Transportation Economics, 5: 1-52.

Diewert, W.E., and T. J. Wales (1987) "Flexible Functional Forms and Global Curvature Conditions," Econometrica, 55: 43-68.

Ellig, Jerry (2002) "Railroad Deregulation and Consumer Welfare," Journal of Regulatory Economics, 21: 143-168.

European Commission, Directorate-General for Economic and Financial Affairs (2000) Liberalisation of Network Industries. Economic Implication and Main Policy Issues. Reports and Studies, $\mathrm{N}^{\circ} 4$.

Evans, David. and Heckman, James (1984) "A Test of Subadditivity for the Cost Function with an Application to the Bell System," American Economic Review, 6: 15-23.

Fraquelli, Giovanni, Massimiliano, Piacenza and Davide Vannoni (2005) "Cost Savings from Generation and Distribution with an Application to Italian Electric Utilities," Journal of Regulatory Economics, 28: 289-308. 
Ivaldi, Marc and McCullough, Gerard (2001) "Density and Integration Effects on Class I U.S. Freight Railroads," Journal of Regulatory Economics, 19: 161-182.

Kaserman, David L., and Mayo, John W. (1991) "The Measurement of Vertical Economies and the Efficient Structure of the Electric Utility Industry," Journal of Industrial Economics, 39: 483-500.

Kumbhakar, Subal C. (1994) "A Multiproduct Symmetric Generalized McFadden Cost Function," Journal of Productivity Analysis, 5: 349-357.

McFadden, Daniel L. (1978) "Cost, Revenue, and Profit Functions," in D. L. McFadden and Melvin Fuss (ed.), Production Economics, North-Holland: Amsterdam.

Panzar, John C. (1989) “Technological Determinants of Firm and Industry Structure," in Schmalensee, R. and R. D. Willig (ed.), Handbook of Industrial Organization, North-Holland: Amsterdam.

Pittman, Russell (2005) "Structural Separation to Create Competition? The Case of Freight Railways," Review of Network Economics, 4: 181-196.

Roller, Lars-Hendrik (1990) "Proper Quadratic Cost Functions with An Application to the Bell System," Review of Economics and Statistics, 72: 202-210.

Shin, R.T. and J. S. Ying (1980) "Unnatural Monopolies in Local Telephone," Rand Journal of Economics, 23: 171-183.

Teece, David J. (1980) "Economies of Scope and the Scope of Enterprise," Journal of Economic Behavior and Organization, 1: 223-247.

Wiley, David E., Schmidt, William H., and Bramble, William J. (1973) "Studies of a Class of Covariance Structure Models," Journal of the American Statistical Association, 68: 317-323.

Wilson, Wesley W. (1997) "Cost Savings and Productivity in the Railroad Industry," Journal of Regulatory Economics, 11: 21-40. 


\section{$7 \quad$ Appendix}

\begin{tabular}{|c|c|c|c|c|c|}
\hline Railroad & Acronym & Period & Railroad & Acronym & Period \\
\hline Santa Fe & ATSF & $78-95$ & $\begin{array}{l}\text { Louisville \& } \\
\text { Nashville }\end{array}$ & $\mathrm{LN}$ & $78-82$ \\
\hline Baltimore \& Ohio & $\mathrm{BO}$ & $78-83$ & $\begin{array}{l}\text { Missouri-Kansas-T } \\
\text { exas }\end{array}$ & MKT & $78-87$ \\
\hline $\begin{array}{l}\text { Burlington } \\
\text { Northern }\end{array}$ & $\mathrm{BN}$ & 78-01 & Missouri Pacific & MP & $78-85$ \\
\hline $\begin{array}{l}\text { Chesapeake \& } \\
\text { Ohio }\end{array}$ & $\mathrm{CO}$ & $78-83$ & $\begin{array}{l}\text { Norfolk \& } \\
\text { Western }\end{array}$ & NW & $78-83$ \\
\hline $\begin{array}{l}\text { Chicago } \\
\text { Northwestern }\end{array}$ & $\mathrm{CNW}$ & $70-94$ & Norfolk Southern & NSC & $86-97$ \\
\hline Consolidated Rail & $\mathrm{CRC}$ & $70-98$ & Seaboard Coastline & SCL & $78-85$ \\
\hline CSX Corp & CSX & $86-01$ & Soo Line & $\mathrm{SOO}$ & $78-01$ \\
\hline $\begin{array}{l}\text { Denver \& Rio } \\
\text { Grande }\end{array}$ & DRGW & $78-93$ & Southern Pacific & $\mathrm{SP}$ & $78-96$ \\
\hline Grand Trunk & GTW & 87-01 & Southern Railway & SRS & $78-85$ \\
\hline $\begin{array}{l}\text { Illinois Central } \\
\text { Gulf }\end{array}$ & ICG & 78-01 & Union Pacific & UP & $78-85$ \\
\hline $\begin{array}{l}\text { Kansas City } \\
\text { Southern }\end{array}$ & $\mathrm{KCS}$ & $78-01$ & $\begin{array}{l}\text { Union Pacific } \\
\text { System }\end{array}$ & UPSYS & $86-01$ \\
\hline
\end{tabular}

Table A1: U.S. Class I railroads 1978 - 2001

\begin{tabular}{lllll}
\hline Equation & SSE & Root MSE & Durbin Watson & R-Square \\
\hline$X_{L}$ & 440296 & 663.5 & 0.9528 & 0.9802 \\
$X_{F}$ & 49014 & 221.4 & 1.4552 & 0.9921 \\
$X_{E}$ & 1086831 & 1042.5 & 1.5354 & 0.9320 \\
$X_{M}$ & 67263.1 & 259.4 & 1.1419 & 0.9574 \\
$\log \left(y_{B}\right)$ & 0.0970 & 0.3115 & 0.5418 & 0.9347 \\
$\log \left(y_{E}\right)$ & 0.2016 & 0.4490 & 0.2402 & 0.8510 \\
$\log \left(y_{I}\right)$ & 0.1342 & 0.3663 & 1.1259 & 0.8783 \\
\hline
\end{tabular}

Table A2: Nonlinear FIML summary 